\title{
STUDI MEKANISME KINETIK DENGAN PARAMETRIK CAMSHAFT PADA SELUBUNG BANGUNAN ADAPTIF
}

\author{
Firza Utama Sjarifudin \\ Architecture Department, Faculty of Engineering, Binus University \\ Jl. K.H. Syahdan No. 9, Palmerah, Jakarta Barat 11480 \\ fsjarifudin@binus.edu
}

\begin{abstract}
Adaptation is essential to manage the problem of climate change. In order to meet the challenge, this paper proposes an adaptive building envelope system that can optimize its configuration by responding environmental changes to achieve new levels of sustainable performance and energy efficiency. Most current adaptive building envelope uses kinetic techniques make its formation transformable. However, the use of kinetic components such as a large amount of interactive motorized system that requires electrical power may also cause further decrease the building energy efficiency. This paper proposes a camshaft mechanism system for adaptive building envelope that uses less motors, controllers, and sensors. This system uses pre-programmed analysis data of daily solar radiation changes to parametrically drive the number of rotation phase and length of nose (Lobe Lift) that generates the shape of camshaft. The camshaft then controls the values of opening and closing of the building envelope components. The advantages of this system are less energy consumption, less maintenance and lower cost since it uses fewer motors, controllers and wiring. In conclusion, this paper has developed a prototypical tool that facilitates a new approach to energy-efficient kinetic buildings.
\end{abstract}

Keywords: adaptive building envelope; camshaft mechanism; energy efficiency; kinetic building

\begin{abstract}
ABSTRAK
Adaptasi merupakan suatu hal yang penting dalam menghadapi masalah perubahan iklim. Untuk memenuhi tantangan yang berkembang, makalah ini mengusulkan sebuah sistem sistem selubung bangunan adaptif yang dapat menanggapi perubahan lingkungan untuk mencapai tingkat kinerja baru dalam efisiensi energi. Sebagian besar komponen adaptif menggunakan teknik kinetik yang menggunakan banyak sistem bermotor sehingga membutuhkan tenaga listrik untuk menggerakkannya, sistem semacam ini dapat menyebabkan penurunan dalam efisiensi energi. Makalah ini mengusulkan sebuah sistem mekanisme camshaft untuk selubung bangunan adaptif yang menggunakan lebih sedikit motor, pengendali, dan sensor. Sistem ini menggunakan analisis data parametrik terhadap perubahan radiasi matahari untuk mendorong jumlah fase rotasi dan panjang hidung (Lobe Lift) yang menghasilkan bentuk camshaft. Camshaft ini kemudian mengendalikan nilai-nilai pembukaan dan penutupan dari komponen selubung bangunan. Keuntungan dari sistem ini adalah penekanan dalam hal pengkonsumsian energi, pemeliharaan, dan biaya karena menggunakan lebih sedikit motor, controller dan kabel. Sebagai kesimpulan, makalah ini menunjukkan pengembangan prototype alat yang merupakan suatu pendekatan baru untuk bangunan kinetik hemat energi.
\end{abstract}

Kata kunci: selubung bangunan adaptif, camshaft mechanism, efisiensi energi, bangunan kinetik 


\section{PENDAHULUAN}

Kebanyakan orang menghabiskan hingga 90\% dari waktu mereka di dalam ruangan (Bougdah) sehingga banyak usaha yang dilakukan untuk membuat bangunan yang aman, sehat dan senyaman mungkin. Bukaan merupakan elemen penting pada bangunan untuk memasukkan cahaya alami kedalam bangunan.

Dengan perkembangan teknologi yang ada saat ini dinilai sangat penting untuk mempertimbangkan kembali bukaan pencahayaan pada bangunan yang dapat mengontrol konsumsi energi bangunan dan kualitas kenyamanan visual dalam ruangan. Secara tradisional, kebanyakan bukaan pencahayaan bersifat 'statis', sedangkan kondisi pergerakan matahari dan preferensi pengguna yang terus berubah. Akibatnya sistem bukaan pencahayaan tradisional tidak dapat beradaptasi dengan perubahan itu, dan ini mengakibatkan hilangnya kesempatan untuk penghematan energi dan meningkatkan kenyamanan visual penghuni.

Sistem bukaan pencahayaan kinetik yang ditawarkan dalam penelitian ini, di sisi lain mendefinisikan bukaan dengan cara yang berbeda secara mendasar. bukaan dengan sistem kinetik secara aktif dapat menyesuaikan perilaku bentuk dari waktu ke waktu sebagai respon terhadap perubahan kondisi lingkungan dan persyaratan kinerja. Bukaan dengan sistem kinetik memiliki kemampuan untuk memanfaatkan cahaya alami yang tersedia di lingkungan kita dengan cara yang jauh lebih efektif. Bukaan dengan sistem kinetik tidak hanya menawarkan potensi untuk mengurangi penggunaan energi untuk penerangan, tapi pada saat yang sama juga diharapkan untuk dapat menghasilkan kontribusi positif terhadap kualitas dan tingkat kenyamanan termal dan visual.

Studi terbaru menunjukkan bahwa rancangan selubung bangunan yang tepat dengan pengontrolan secara simultan penggunaan listrik untuk pencahayaan dan komponen HVAC, secara signifikan dapat mengurangi beban pendinginan dan konsumsi energi (Tzempelikos, 2007). Selain itu makin banyak juga studi untuk memasukkan kecerdasan pada bangunan agar penghematan energi dapat semakin baik. Desain arsitektur "pintar" banyak menggunakan perangkat teknologi cerdas, fitur aktif pada elemen bangunan yang dapat menyesuaikan diri dengan perubahan yang dipengaruhi oleh lingkungan sekitar (Ochoa dan Capeluto, 2008). Dengan fasade bergerak dan membuatnya dinamis, dapat menjadikannya lebih mampu beradaptasi dengan kondisi dan meningkatkan kenyamanan penghuni. Fasade sekarang dapat mendeteksi kondisi lingkungan dan mampu memodifikasi sendiri untuk mencapai tujuan yang ditentukan. Bangunan dapat terus bekerja menuju lingkungan yang lebih baik bagi pengguna dibandingkan dengan hanya melindungi mereka secara pasif (Hansanuwat, 2010). Dengan mempelajari banyak sistem bangunan kinetik yang ada dan melalui penggunaan simulasi komputer dan pengujian empiris, contoh dari metode gerakan kinetik dapat dianalisis untuk dibandingkan satu sama lain, dan menghasilkan output usulan yang terbaik dalam penghasilan bentuk (Skavara, 2009). Metode desain parametrik secara efektif dapat membuat pemodelan bangunan dan konfigurasinya terhubung ke dunia nyata melalui parameter iklim, yang dapat menawarkan cara penting untuk mengeksplorasi komponen bangunan kinetik (Wang dan Li, 2010; Wang, et al., 2010).

Para peneliti di atas telah dijelaskan bahwa penggerak utama untuk bangunan adaptif dan kinetik adalah tema sustainability dan efisiensi energy. Namun pengembangan dan penerapan teknologi tinggi dilihat lambat, kebanyakan arsitek skeptis melihat komponen kinetik yang kemudian dibuang dari bangunan mereka karena kinerja yang buruk, aktuator rusak atau tingginya biaya pemeliharaan, dengan ini dapat dilihat bahwa perwujudan bangunan kinetik adalah suatu tantangan yang berat (Sullivan, 2006).

Studi-studi literatur mengenai masalah bangunan kinetik dan adaptif diatas mendorong penelitian ini dengan wawasan praktis dan berkelanjutan mengenai bagaimana mengeksplorasi dan 
mewujudkan bangunan adaptif yang lebih baik. Keaslian dari makalah ini adalah dalam hal pegembangan sistem baru untuk sistem adaptif yang lebih hemat energi dan dapat lebih banyak digunakan secara umum untuk meningkatkan jumlah bangunan yang tanggap lingkungan.

\section{METODE}

Makalah ini merupakan penelitian awal dari target penelitian multi-tahun dalam pengembangan selubung bangunan adaptif yang lebih efektif dan efisien dan memungkinkan untuk diproduksi untuk bangunan yang lebih umum. Tahap penelitian dalam makalah ini lebih difokuskan pada pengembangan prototipe virtual dan simulasi.

\section{Camshaft vs Parametric Camshaft}

Camshaft merupakan sebuah batang shaft di mana pada shaft tersebut dipasangkan beberapa buah Cam yang menjadi satu kesatuan. Sebuah Cam merupakan objek pemutar dalam sebuah sambungan mekanikal terutama digunakan untuk mengubah gerakan memutar menjadi gerakan linear (naik-turun) (Wilson, 2002). Camshaft biasanya digunakan dalam pengontrolan gerakan katup pada sebuah mesin kendaraan bermotor. Bagian penting dari sebuah Cam adalah: base circle, nose, lobe lift, and duration (Gambar 1, Mehlhoff, 2011). Parts tersebut akan dimanfaatkan dalam penelitian ini sebagai modul dalam penghasilan bentuk parametric camshaft.

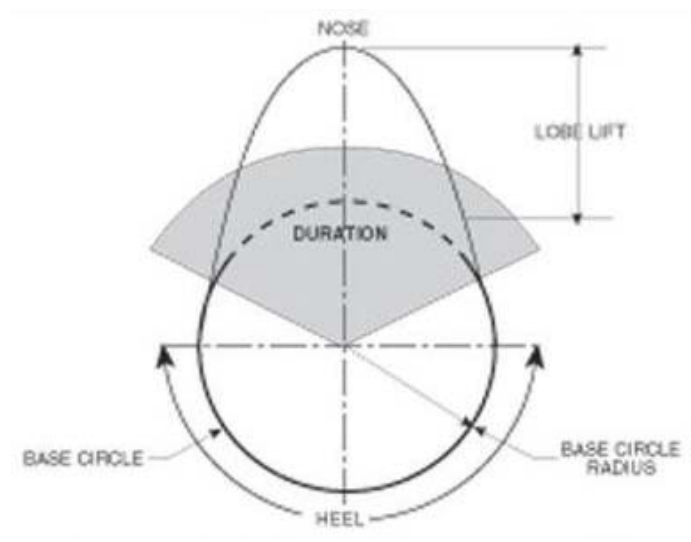

Gambar 1. Profil Cam yang digunakan dalam mesin kendaraan.

Yang membedakan parametric camshaft dalam penelitian ini adalah penggunaan multiple Nose dan Lobe lift pada setiap cam-nya. Hal ini akan menghasilkan gerakan non-linear dan berubahubah. Cam tersebut akan mengontrol besarnya bukaan dari setiap panel dari building envelope.

Parameter utama dalam parametric camshaft ini adalah panjang Lobe Lift (L), dan jumlah Duration (P). Setiap L dan P tersebut mempunyai nilai yang bervariasi, dan besaran nilai tersebut ditentukan dari hasil simulasi solar radiation. Gambar 2 memperlihatkan profil parametric cam yang akan digunakan dalam penelitian ini. 


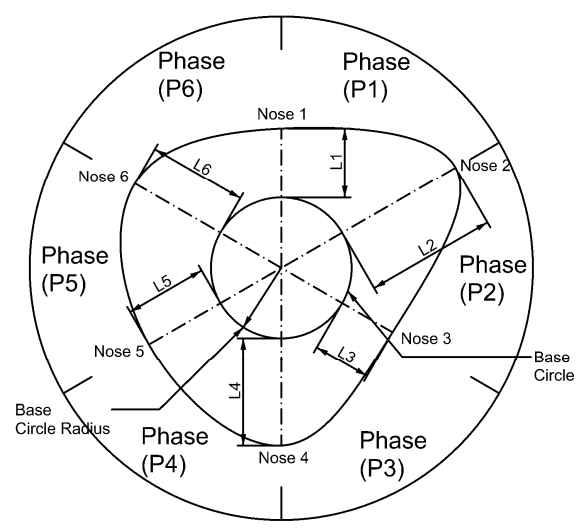

Gambar 2. Profil parametrik cam yang diterapkan pada masing-masing panel adaptif.

\section{HASIL DAN PEMBAHASAN}

\section{Solar Radiation dan Mekanisme Parametrik Cam}

Simulasi solar radiation pada lokasi spesifik dilakukan untuk menghasilkan nilai-nilai yang mengatur parameter bentuk camshaft. Setting lokasi yang diambil adalah di kota Jakarta, Indonesia (6. $16 \mathrm{~S}, 106.48 \mathrm{~W}$ ), weather data taken from 2008. Kondisi iklim di lokasi ini adalah tropis di mana perubahan cuaca dalam setahun tidak terlalu drastis, sehingga dalam penelitian ini difokuskan pada penanganan perubahan setiap jam dalam satu hari.

Penelitian diawali dengan menentukan jenis building envelope yang digunakan sebagai kasus. Bentuk permukaan lengkung diambil untuk penelitian ini karena pada jenis permukaan tersebut menerima besaran radiasi matahari yang bervariasi sehingga cukup efektif dalam melihat perubahan yang terjadi. Ukuran yang diambil adalah lebar $=14 \mathrm{~m}$, panjang $=18 \mathrm{~m}$, tinggi $=5 \mathrm{~m}$. Orientasi bangunan menghadap ke Barat. Pertama, permukaan tersebut di bagi menjadi grid 10 x 10 yang merepresentasikan panel-panel adaptif. Kemudian pada permukaan tersebut dilakukan perhitungan solar access analysis dari jam 6:00 AM sampai jam 6:00 PM untuk satu tahun menggunakan program Autodesk Ecotect Analysis 2011. Gambar 3 memperlihatkan salah satu hasil dari simulasi.

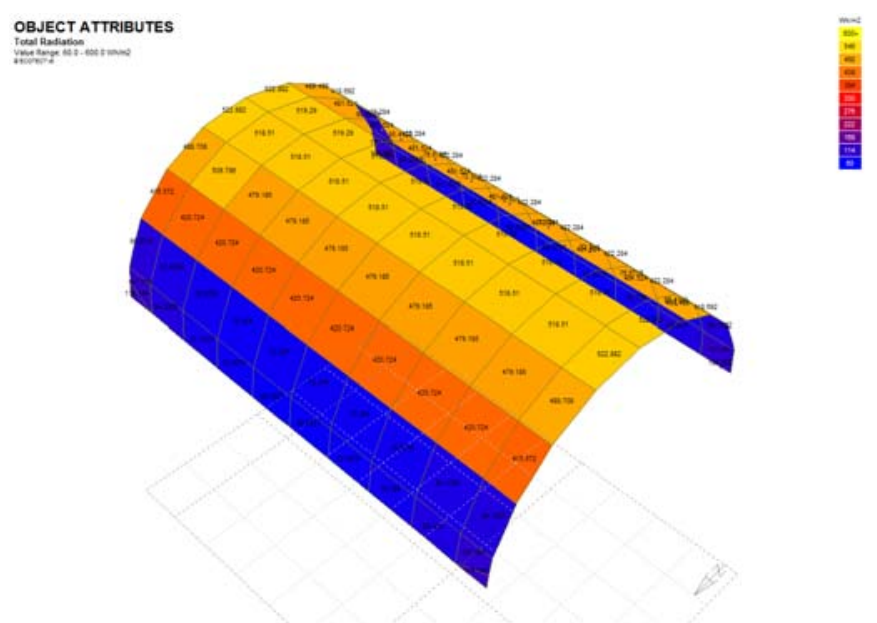

Gambar 3. Salah satu hasil dari simulasi radiasi matahari pada permukaan lengkung. 
Hasil dari perhitungan simulasi tersebut kemudian diambil average untuk setiap jamnya sehingga didapat nilai perubahan radiasi matahari selama 12 jam untuk setiap gridnya. Nilai average terendah adalah $000.000 \mathrm{WH} / \mathrm{m}^{2}$ dan yang tertinggi adalah $000.000 \mathrm{WH} / \mathrm{m}^{2}$, nilai-nilai tersebut kemudian digunakan sebagai parameter penentu panjang L dan jumlah P. Untuk dapat menghasilkan perhitungan dan pengaturan parameter tersebut digunakan software Algorithmic Editor "Grasshopper" yang merupakan plug-in dari CAD software Rhinoceros. Gambar 4 memperlihatkan hubungan parametric yang dibuat dalam Grasshopper.

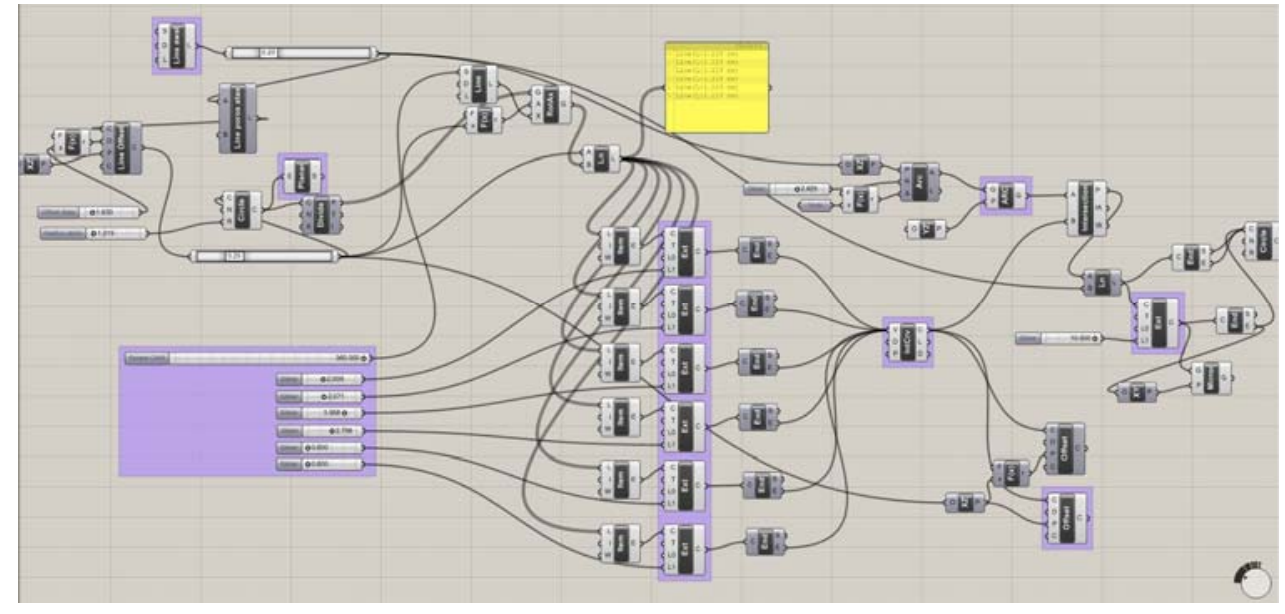

Gambar 4. Pengontrolan parameter dan hubungan komponen dalam Grasshopper.

Algoritma yang dibuat adalah di mana pada nilai radiasi terendah akan menghasilkan nilai $\mathrm{L}$ yang kecil mengakibatkan mekanisme menutup pada panel, sedangkan pada nilai radiasi yang tinggi akan menghasilkan nilai L yang besar mengakibatkan mekanisme terbuka pada panel. Kemudian jumlah perubahan radiasi yang signifikan terjadi dalam satu hari digunakan sebagai penentu jumlah $\mathrm{P}$ dalam satu cam. Dalam hal ini perubahan nilai radiasi yang signifikan pada salah satu panel adalah 5 kali, sehingga junlah $\mathrm{P}=5$. Gambar 5 memperlihatkan variasi dari nilai $\mathrm{L}$ dan $\mathrm{P}$ pada beberapa cam.
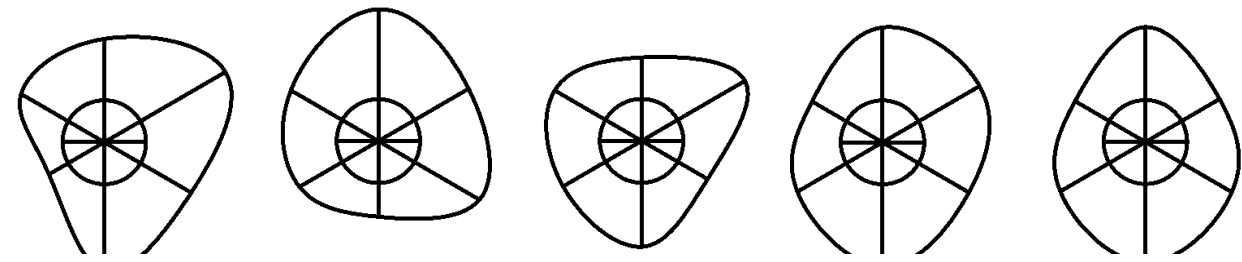

Gambar 5. Variasi nilai L dan P pada tiap cam yang menghasilkan bentuk yang berbeda dari masing-masing cam.

Bentuk cam yang dihasilkan kemudian dihubungkan dengan sebuah mekanisme penggerak berbentuk garis lengkung dengan sudut $90^{\circ}$ (A) yang akan menghasilkan gerakan 1/4 lingkaran. Pergerakan sepanjang garis lengkung tersebut kemudian dihubungkan ke poros pusat (C) untuk menggerakkan panel membuka atau menutup. Gambar 6 memperlihatkan mekanisme penggerak panel. Selanjutnya, penggabungan putaran cam dengan bentuk yang spesifik dan driver mechanism akan menghasilkan gerakan membuka-menutup secara bervariasi sesuai dengan panjang L dan jumlah P seperti ditunjukkan pada Gambar 7. 


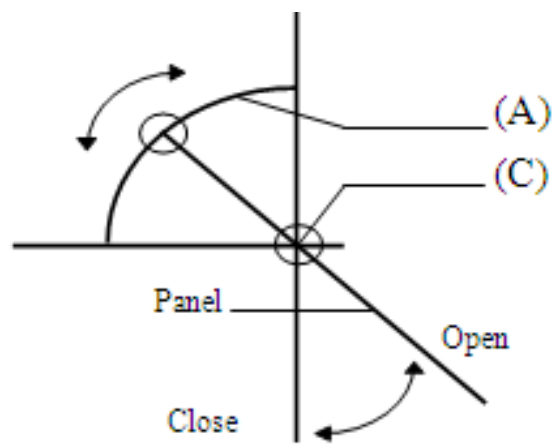

Gambar 6. Mekanisme untuk membuka dan menutup panel selubung bangunan.
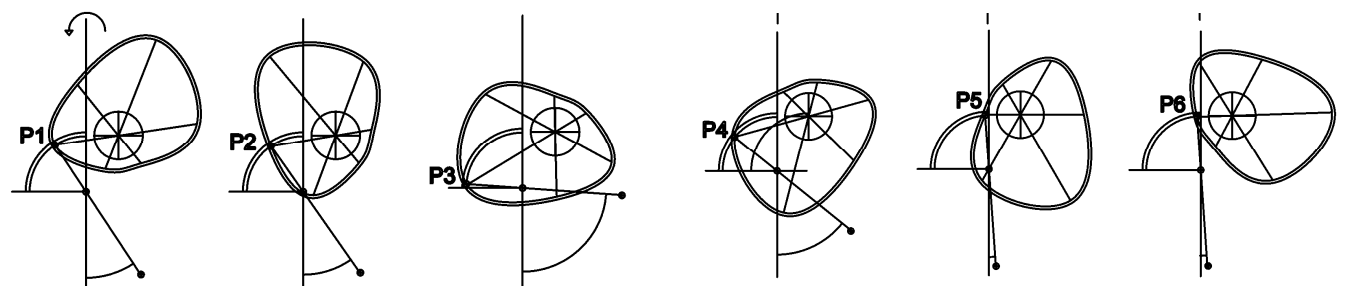

Gambar 7. Gerakan perputaran cam dengan 6 fase perubahan.

Contoh pengembangan bentuk panel yang akan diterapkan menggunakan prinsip jalusi yaitu dengan mekanisme buka tutup yang terbuat dari deretan slats (tirai jendela). Slats ini akan membuka dua arah terbalik dan sudut bukaannya adalah $0^{\circ}-90^{\circ}$. Besar sudut bukaan tersebut ditentukan dari panjang L dari cam yang sudah disesuaikan dari nilai hasil simulasi solar radiation. Pembukaan slats dengan 2 arah terbalik ini juga dapat berfungsi sebagai pengarah pantulan sinar matahari agar sesuai dengan kualitas pencahayaan yang dibutuhkan ruang dalam bangunan untuk mengatasi efek silau as seperti yang terlihat pada Gambar 8.

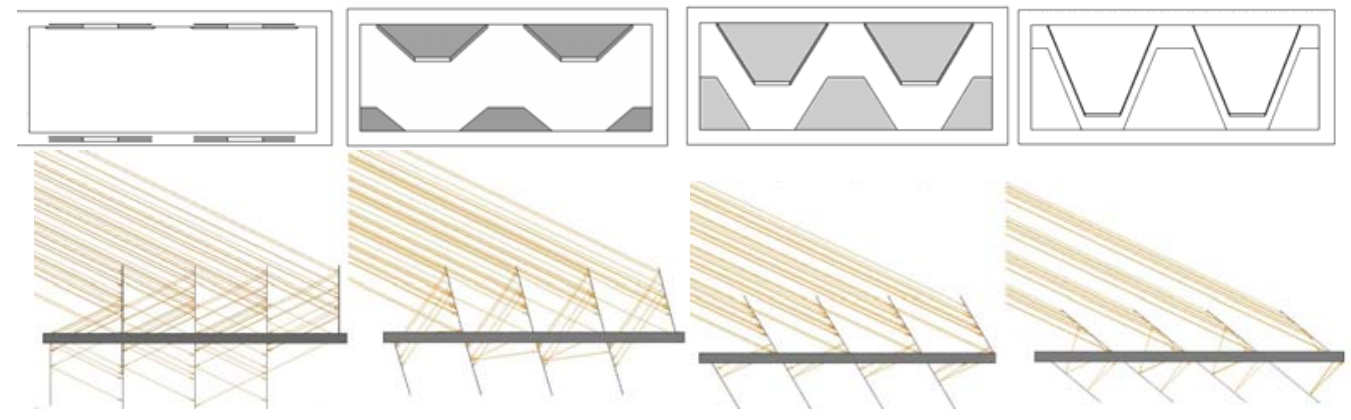

Gambar 8. Bukaan 2 arah pada panel adaptif.

Selanjutnya adalah pengoperasian camshaft yang digerakkan dengan menggunakan motor. Deretan cam yang akan menggerakkan setiap panel dipasangkan dalam camshaft yang berada pada deretan lurus permukaan. Dalam hal ini, satu camshaft terdapat 10 cam. Setiap camshaft tersebut akan digerakkan oleh motor stepper yang berputar mengikuti jumlah P. Putaran penuh (360 $)$ akan dibagi dengan jumlah P dalam waktu on selama 12 jam, kemudian off selama 12 jam, dan akan berulang seterusnya. Pengaturan ini dilakukan dalam microcontroller yang mendapat input data dari Grashopper (Gambar 4) dengan plug-in Firefly (Johnson dan Payne, 2010) yang menyambungkan data dari 
Grasshopper ke microcontroller untuk menggerakkan motor. Gambar 9 memperlihatkan bentuk sederhana dari parametric camshaft.

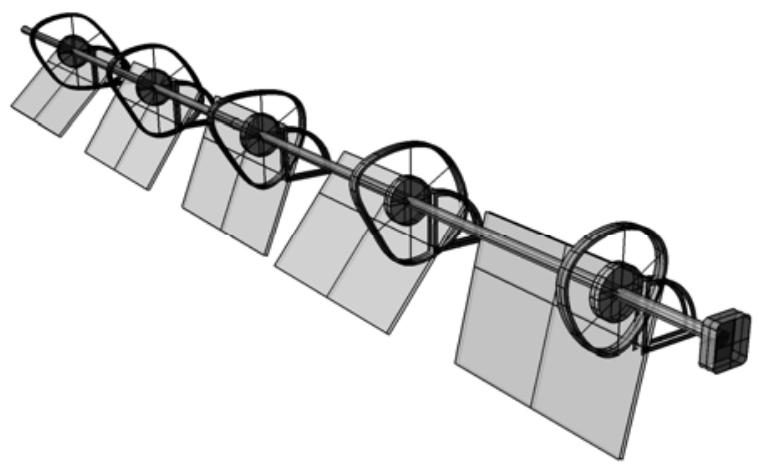

Gambar 9. Bentuk sederhana parametric camshaft.

Terakhir, masing-masing panel dengan bukaan yang spesifik diletakkan pada permukaan lengkung. Dalam 1 hari permukaan ini akan berubah mengikuti perubahan radiasi matahari seperti yang terlihat pada Gambar 10.
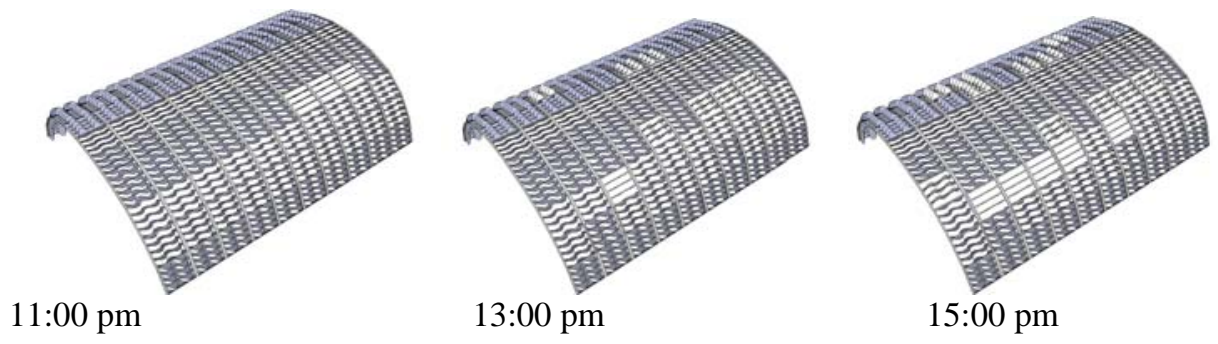

Gambar 10. Beberapa perubahan yang terjadi pada permukaan.

\section{Evaluasi}

Efisiensi dari sistem ini dapat dilihat dengan membandingkan sistem yang banyak digunakan yaitu Distributed Motorized System (DMS). Sistem DMS menggunakan peralatan seperti sensor, mikrokontroler, driver dan motor dalam jumlah yang banyak untuk menggerakkan setiap panel. Cara kerjanya adalah dari sensor yang menangkap kondisi lingkungan yang adasebagai data input untuk diproses dalam mikrokontroler untuk menggerakkan motor melalui driver seperti yang terlihat pada Gambar 11. Energi listrik yang banyak digunakan pada sistem ini adalah untuk pengoperasian motor yang berjumlah banyak.

Sebaliknya, Centralized Motorized System (parametric camshaft) menggunakan data analisa simulasi lingkungan yang menggantikan sensor. Motor yang digunakan lebih sedikit yaitu hanya 1 pada setiap deretnya sehingga mengurangi juga jumlah driver (Gambar 12). Dengan ini energi listrik yang digunakan dapat ditekan.

Selain itu dari segi perawatan pada sistem DMS apabila motor perlu diganti atau service maka dari jumlah, letak dan pemasangannya akan sangat menyulitkan. Sedangkan sistem parametrik camshaft lebih menggunakan peralatan mekanikal sehingga pemasangan dan perawatan mudah dilakukan, dan jika diperlukan penggantian akan memudahkan karena tidak memakai kabel.

Dari semua itu kelebihan sistem ini dapat dilihat pada segi biaya yang dapat ditekan dari saat pembuatan, pengoperasian, dan perawatan. 


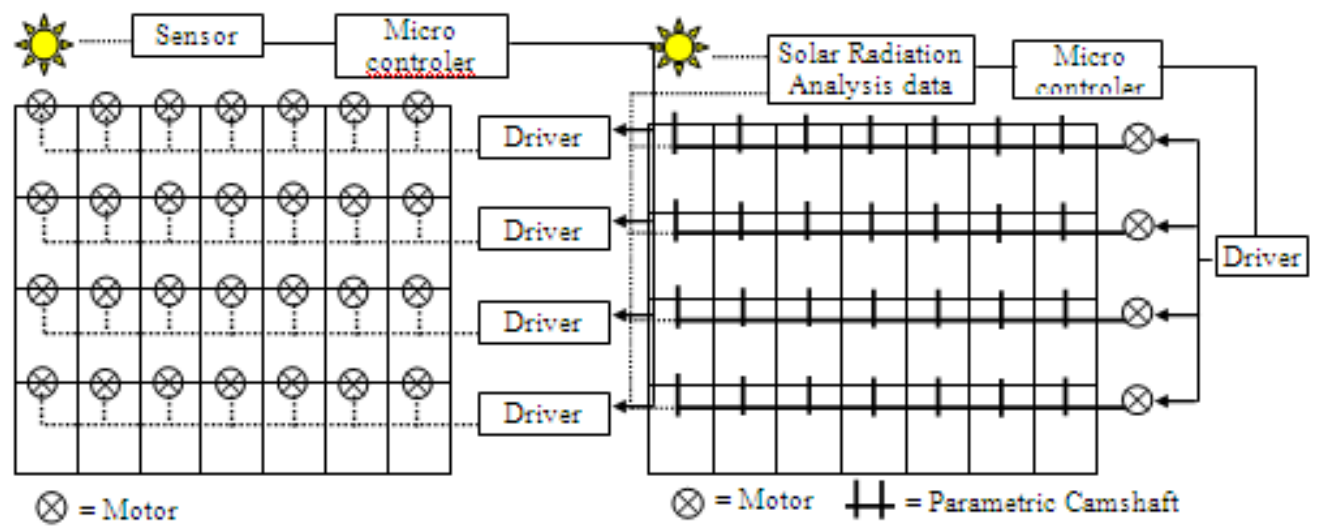

Gambar 11. Distributed Motorized System. Gambar 12. Skema Sistem Parametric camshaft System.

\section{PENUTUP}

Penelitian ini telah memperlihatkan efektifitas penggunaan parametric camshaft untuk pengontrolan mekanisme kinetiK dalam selubung bangunan atau fasade adaptif.

Efektifitas dari sistem ini dinilai lebih lebih baik diterapkan pada daerah beriklim tropis di mana perubahan yang terjadi sepanjang tahun tidak terlalu banyak. Sebagai contoh jika bangunan pada iklim tropis menggunakan sistem adaptif yang dirancang untuk daerah empat musim, akan terlihat adanya pemborosan, dan penghematan energi yang dapat dicapai tidak akan banyak jika dibandingkan dengan kebutuhan energi untuk pengoperasian sistem tersebut.

Dalam hal biaya yang lebih ekonomis, sistem ini dapat diterapkan pada bangunan-bangunan umum sehingga lebih banyak pengguna yang dapat merasakan kelebihan dan keuntungan dari sistem bangunan adaptif. Untuk riset lanjutannya akan dilakukan pada penerapan material dan rancangan fisik. Target yang ingin dicapai adalah penemuan jenis material yang efektif dari segi ketahanan dan biaya. Dari segi rancangan fisik target yang ingin dicapai adalah kemudahan dalam perakitan dan perawatan. Rencana lain dari kelanjutan riset ini adalah dengan membuat prototipe dengan skala 1:1, yang kemudian dengan prototipe ini akan dilakukan pengujian langsung terhadap kondisi lingkungan sesungguhnya untuk dilakukan beberapa penyesuaian dan temuan-temuan lain yang dapat meningkatkan efisiensi dan efektifitas sistem ini. Target utama yang ingin dicapai dari semua aspek tersebut adalah terciptanya tingkat sustainability dan efisiensi energi yang tinggi.

\section{DAFTAR PUSTAKA}

Hansanuwat, R. (2010). Kinetic Facades as Environmental Control Systems: Using Kinetic Facades to Increase Energy Efficiency and Building Performance in Office Buildings. Tesis tidak diterbitkan, University of Southern California.

J. Wang dan J. Li. (2010). Bio-inspired kinetic envelope for building energy efficiency based on parametric design of building information modeling. Power and Energy Engineering Conference, IEEE.

J. Wang, J. Li, X. Chen, (2010). Parametric design based on building information modeling for 
sustainable buildings. International Conference on Challenges in Environmental Science and Computer Engineering, IEEE.

Johnson, J.K. dan Payne, A. (2010). Firefly Primer - Firefly Version 1.003.

Mehlhoff, B. (2011). Understanding Camshaft. Diakses Oktober 2012 dari http://tinyurl.com/7zjlb6z.

Ochoa, C.E., Capeluto, I.G. (2008). Strategic decision- making for intelligent buildings: Comparative impact of passive design strategies and active features in a hot climate. Building and Environment, 43, 829-1839.

Skavara, M.E. (2009). Learning Emergence, Adaptive Cellular Automata Façade Trained by Artificial Neural Networks. Tesis tidak diterbitkan, Bartlett UCL.

Sullivan, C.C. (2006). Robo buildings: Pursuing the interactive envelope. Architectural Record, 0003858X, 194, issue 4.

Tzempelikos, T. (2007). Integration of dynamic facades with other building systems. Automated Buildings Magazine, May.

Wilson, A. (2002). Machines, power and the ancient economy. The Journal of Roman Studies, 92, 1 32. 